\title{
Inhibition of aluminum corrosion in acid solution by mono- and bis-azo naphthylamine dyes. Part 1
}

\author{
E.M. MABROUK ${ }^{1,2}$, H. SHOKRY ${ }^{1 *}$, K.M. ABU AL-NAJA ${ }^{1}$ \\ ${ }^{1}$ Chemistry Department, Faculty of Applied Science, Umm-Al Qura University, Makkah, KSA \\ ${ }^{2}$ Chemistry Department, Faculty of Science, Kafer El-Sheikh University, Kafer El-Sheikh, Egypt \\ * Corresponding author.E-mail:drheshokry@yahoo.com
}

Received August 21, 2010; accepted May 18, 2011; available on-line November 8, 2011

The effect of a series of mono- and bis-azo dyes derived from dihydroxynaphthalene on the dissolution of aluminum in $2 \mathrm{M} \mathrm{HCl}$ solutions was studied using weight loss, thermometry and galvanostatic polarization techniques. The inhibition efficiency was found to increase with increasing concentration of inhibitor to reach $97.86 \%$ for $1 \times 10^{-4} \mathrm{M}$. The inhibition mechanism is discussed on the basis of adsorption of inhibitor molecules on the metal surface. The inhibitors were adsorbed on the surface according to the Temkin adsorption isotherm. The effect of temperature on the corrosion inhibition of Al was studied and thermodynamic functions for the dissolution and adsorption processes in the absence and in the presence of the azo dyes were computed and discussed. The results obtained from the chemical and electrochemical measurements are in good agreement.

Naphthylamineazo dye / Aluminum / Inhibitors / Weight loss / Thermometry / Polarization

\section{Introduction}

Aluminum and its alloys are widely used in technology because of their low density, pleasing appearance, and corrosion resistance. For these reasons, the corrosion inhibition of $\mathrm{Al}$ in aqueous solution has attracted the attention of many investigators [1-9]. Inhibition of metal corrosion by organic compounds is the result of adsorption of organic molecules or ions on the metal surface, forming a protective layer. This layer reduces or prevents the corrosion of the metal. The extent of adsorption depends on the nature of the metal, the condition of the metal surface, the mode of adsorption, the chemical structure of the inhibitor, and the type of corrosive media [10].

Among the numerous methods used in combating corrosion problems, the use of chemical inhibitors remains the most cost effective and practical method. The development of corrosion inhibitors based on organic compounds containing nitrogen, sulfur and oxygen atoms is of growing interest in the field of corrosion and industrial chemistry, as corrosion poses serious problems to the service lifetime of alloys used in industry [11]. The stability of the adsorbed inhibitor films formed on the metal surface to protect the metal from corrosion depends on physico-chemical properties of the molecule related to its functional groups, such as aromaticity, possible steric effects, electron density of donor atoms, as well as on the type of corrosive medium and the nature of the interaction between the inhibitor and the metal surface [12-14].

In this paper we present a first evaluation of the corrosion protection effect of mono- and bisnaphthylamineazo dyes on the dissolution of aluminum in $2 \mathrm{M} \mathrm{HCl}$ solutions by using weight loss, thermometry and polarization measurements. Thermodynamics was used to properly characterize the mechanism of the corrosion process.

\section{Materials and methods \\ 2.1 Materials}

Aluminum metal with a purity of 99.94 wt.\% from Aldrich having the chemical composition given in Table 1 was used in the present study. Aluminum sheets with a surface of $1 \mathrm{~cm}^{2}$ were used for the weight loss measurements. For the thermometric measurements pieces of aluminum metal measuring $1 \times 5 \mathrm{~cm}$ were used. For the polarization studies a cylindrical rod embedded in araldite with an exposed surface of $1 \mathrm{~cm}^{2}$ was used. The electrodes in all the measurements were polished with 1-, 0- and 00-emery paper, degreased with acetone and rinsed with distilled water. 
E.M. Mabrouk et al., Inhibition of aluminum corrosion in acid solution by mono- and bis-azo naphthylamine dyes...

Table 1 Chemical composition of aluminum.

\begin{tabular}{c|c|c|c|c|c|c|c|c|c|c|c}
\hline Element & $\mathrm{C}$ & $\mathrm{Mn}$ & $\mathrm{P}$ & $\mathrm{Si}$ & $\mathrm{N}$ & $\mathrm{V}$ & $\mathrm{Ti}$ & $\mathrm{Ca}$ & $\mathrm{Cr}$ & other & $\mathrm{Al}$ \\
\hline $\begin{array}{c}\text { Weight, } \\
\text { wt.\% }\end{array}$ & 0.046 & 0.175 & 0.008 & 0.009 & 0.003 & 0.00113 & 0.00048 & 0.00006 & 0.0126 & 0.039 & rest \\
\hline
\end{tabular}<smiles>[X]c1ccccc1/N=N/c1c(O)c(O)cc2ccccc12</smiles>

$\mathrm{X}=\mathrm{O}-\mathrm{COOH}(\mathbf{I})$ o- $\mathrm{OCH}_{3}$ (III)

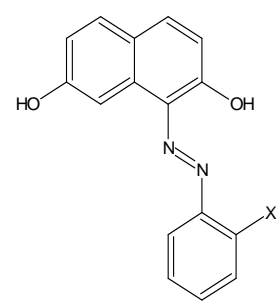

$\mathrm{X}=\mathrm{O}-\mathrm{COOH}(\mathbf{I I})$, $\mathrm{o}-\mathrm{OCH}_{3}(\mathbf{I V})$

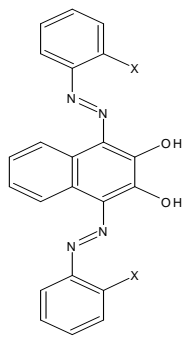

$\mathrm{X}=\mathrm{O}-\mathrm{COOH}(\mathbf{V})$, $\mathrm{o}-\mathrm{OCH}_{3}(\mathrm{VII})$

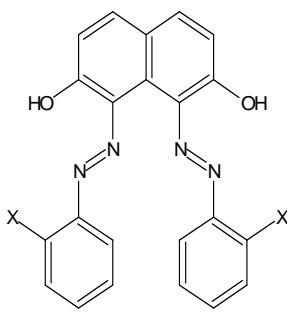

$\mathrm{X}=\mathrm{O}-\mathrm{COOH}(\mathbf{V I})$, o- $\mathrm{OCH}_{3}($ VIII)

Fig. 1 Structural formulas of the mono- and bis-azo dyes tested for inhibition of aluminum corrosion.

\subsection{Synthesis of the organic compounds}

The studied mono-azo dye compounds (inhibitors) were prepared by coupling the diazonium salts of aromatic amine, o-anisidine and anthranilic acid with 0.01 mole of 2,3- and 2,7-dihydroxynaphthalenes, as described elsewhere [15]. The bis-azo dye compounds were prepared in the same manner as the mono-azo dyes, but using 0.005 mole of 2,3- and 2,7-dihydroxynaphthalenes. The prepared azo dyes were characterized by elemental analysis, IR and ${ }^{1} \mathrm{H}-\mathrm{NMR}$ spectra. The structural formulas of the tested compounds are shown in Fig. 1.

All the chemicals used for preparing the test solutions and the azo dyes were of analytical grade (BDH, Analar) and the experiments were carried out at room temperature $30 \pm 1^{\circ} \mathrm{C}$.

\subsection{Methods}

The weight loss measurements were carried out as described elsewhere $[16,17]$. The average weight loss $(\Delta W)$ for two identical experiments was taken and expressed in $\mathrm{mg}$. The corrosion rate $\left(R_{\text {corr }}\right)$ was calculated using Eq. 1:

$$
R_{\text {corr }}=\frac{\Delta W(\mathrm{mg})}{A\left(\mathrm{dm}^{2}\right) \times t(\text { day })}
$$

where $A$ is the surface area of the specimen and $t$ is the period of immersion in the acid solution.

The inhibition efficiency (IE) of the tested azo dyes was calculated using Eq. 2:

$I E=\left[1-\frac{W_{\text {add }}}{W_{\text {free }}}\right] \times 100$ where $W_{\text {free }}$ and $W_{\text {add }}$ are the weights of the metal sheet in the absence and in the presence of the inhibitor. The degree of surface coverage $(\theta)$, which represents the part of metal surface covered by inhibitor molecules, was calculated using Eq. 3:

$\theta=1-\frac{W_{\text {add }}}{W_{\text {free }}}$

The reaction vessel used in the thermometric measurements was basically the same as that described by Mylius [18]. The Mylius vessel was kept in a thermostat to be thermally isolated from the surrounding during the whole experiment. Exactly $15 \mathrm{ml}$ of test solution was used for each experiment. The mercury reservoir of the thermometer was placed on the aluminum specimen. The variation of the temperature of the system was measured as a function of time. The term reaction number $(R N)$ was used to represent the rate of corrosion in the absence and in the presence of the tested inhibitor. The $(R N)$ was defined by Mylius as:

$$
R N=\frac{T_{\mathrm{m}}-T_{\mathrm{i}}}{t}
$$

where $T_{\mathrm{m}}$ and $T_{\mathrm{i}}$ are the maximum and initial temperatures (in ${ }^{\circ} \mathrm{C}$ ), respectively, and $t$ is the time in minutes elapsed to reach $T_{\mathrm{m}} . I E$ was calculated as the relative reduction of $R N$, using Eq. 5:

$I E=\left[1-\frac{R N_{\text {add }}}{R N_{\text {free }}}\right] \times 100$

where $R N_{\text {free }}$ and $R N_{\text {add }}$ are the reaction numbers for aluminum dissolution in free and inhibited $\mathrm{HCl}$ solutions, respectively.

The galvanostatic polarization measurements were carried out using an EG\&G model 173 potentiostat/galvanostat. A three-compartment cell 
E.M. Mabrouk et al., Inhibition of aluminum corrosion in acid solution by mono- and bis-azo naphthylamine dyes...

Table 2 Corrosion parameters for $\mathrm{Al}$ in $2 \mathrm{M} \mathrm{HCl}$ solutions containing different concentrations of azo compounds I-VIII as determined by the weight loss method.

\begin{tabular}{|c|c|c|c|c|c|c|c|c|c|}
\hline \multicolumn{5}{|c|}{ Mono-azo compounds } & \multicolumn{5}{|c|}{ Bis-azo compounds } \\
\hline Compound & {$[C], \mathrm{M}$} & $\begin{array}{c}C R, \\
\mathrm{mg} / \mathrm{dm}^{3} \text { day }\end{array}$ & $E I$ & $\theta$ & Compound & {$[C], \mathrm{M}$} & $\begin{array}{c}C R \\
\mathrm{mg} / \mathrm{dm}^{3} \text { day }\end{array}$ & $I E$ & $\theta$ \\
\hline \multirow[t]{5}{*}{$\mathbf{I}$} & $1 \times 10^{-6}$ & 101.81 & 66.94 & 0.7390 & \multirow[t]{5}{*}{$\mathbf{V}$} & $1 \times 10^{-6}$ & 59.23 & 84.81 & 0.8481 \\
\hline & $5 \times 10^{-6}$ & 74.09 & 78.73 & 0.8101 & & $5 \times 10^{-6}$ & 40.76 & 89.55 & 0.8955 \\
\hline & $1 \times 10^{-5}$ & 63.58 & 82.31 & 0.8370 & & $1 \times 10^{-5}$ & 22.64 & 94.19 & 0.9419 \\
\hline & $5 \times 10^{-5}$ & 42.21 & 86.444 & 0.8918 & & $5 \times 10^{-5}$ & 12.50 & 96.79 & 0.9679 \\
\hline & $1 \times 10^{-4}$ & 35.14 & 90.99 & 0.9099 & & $1 \times 10^{-4}$ & 6.34 & 97.37 & 0.9737 \\
\hline \multirow[t]{5}{*}{ II } & $1 \times 10^{-6}$ & 128.98 & 73.90 & 0.6694 & \multirow[t]{5}{*}{ VI } & $1 \times 10^{-6}$ & 57.06 & 88.02 & 0.8802 \\
\hline & $5 \times 10^{-6}$ & 82.97 & 81.01 & 0.7873 & & $5 \times 10^{-6}$ & 38.76 & 91.60 & 0.9160 \\
\hline & $1 \times 10^{-5}$ & 69.02 & 83.70 & 0.8231 & & $1 \times 10^{-5}$ & 23.36 & 94.42 & 0.9442 \\
\hline & $5 \times 10^{-5}$ & 52.89 & 89.18 & 0.8644 & & $5 \times 10^{-5}$ & 14.67 & 96.33 & 0.9633 \\
\hline & $1 \times 10^{-4}$ & 34.96 & 91.03 & 0.9103 & & $1 \times 10^{-4}$ & 5.61 & 97.86 & 0.9786 \\
\hline \multirow[t]{5}{*}{ III } & $1 \times 10^{-6}$ & 89.13 & 75.99 & 0.7599 & \multirow[t]{5}{*}{ VII } & $1 \times 10^{-6}$ & 53.80 & 88.02 & 0.8802 \\
\hline & $5 \times 10^{-6}$ & 70.47 & 81.94 & 0.8194 & & $5 \times 10^{-6}$ & 35.86 & 88.63 & 0.8863 \\
\hline & $1 \times 10^{-5}$ & 44.74 & 88.53 & 0.8853 & & $1 \times 10^{-5}$ & 17.75 & 94.42 & 0.9442 \\
\hline & $5 \times 10^{-5}$ & 23.36 & 94.01 & 0.9401 & & $5 \times 10^{-5}$ & 10.23 & 96.23 & 0.9623 \\
\hline & $1 \times 10^{-4}$ & 17.57 & 95.49 & 0.9549 & & $1 \times 10^{-4}$ & 5.07 & 97.86 & 0.9786 \\
\hline \multirow[t]{5}{*}{ IV } & $1 \times 10^{-6}$ & 93.65 & 77.15 & 0.7715 & \multirow[t]{5}{*}{ VIII } & $1 \times 10^{-6}$ & 46.73 & 88.04 & 0.8804 \\
\hline & $5 \times 10^{-6}$ & 57.24 & 85.32 & 0.8532 & & $5 \times 10^{-6}$ & 34.23 & 90.80 & 0.9080 \\
\hline & $1 \times 10^{-5}$ & 35.32 & 90.94 & 0.9094 & & $1 \times 10^{-5}$ & 15.73 & 95.45 & 0.9545 \\
\hline & $5 \times 10^{-5}$ & 21.37 & 94.52 & 0.9452 & & $5 \times 10^{-5}$ & 8.33 & 97.35 & 0.9735 \\
\hline & $1 \times 10^{-4}$ & 16.66 & 95.72 & 0.9572 & & $1 \times 10^{-4}$ & 4.95 & 98.70 & 0.9870 \\
\hline
\end{tabular}

with a saturated calomel reference electrode and a platinum foil auxiliary electrode was used. $I E$ was calculated using the following equation:

$I E=\left[1-\frac{I_{\mathrm{add}}}{I_{\text {free }}}\right] \times 100$

where $I_{\text {free }}$ and $I_{\text {add }}$ are the corrosion current densities in the absence and in the presence of the tested inhibitor, respectively. The surface coverage $(\theta)$ was calculated using Eq. 7:

$\theta=1-\frac{I_{\text {add }}}{I_{\text {free }}}$

\section{Results and discussion}

\subsection{Weight loss measurements}

The corrosion of pure aluminum in hydrochloric acid solutions of different concentrations using the weight loss method indicated that a molarity of $2 \mathrm{M}$ of the acid was optimum for carrying out the corrosion tests. The weight loss in mg was determined in an open system at various time intervals in the absence and in the presence of different concentrations of azo compounds I-VIII. Fig. 2 shows the weight loss vs. time for azo compound $\mathbf{I}$ as a typical example of the tested azo dyes. The corrosion rate and the inhibition efficiency of $\mathrm{Al}$ in $2 \mathrm{M} \mathrm{HCl}$ were calculated using Eqs. 1 and 2 and the data are presented in Table 2.

From the data given in Table 2, it is clear that the corrosion rate of aluminum decreases in the presence of the inhibitors I-VIII, when compared to the blank. This may be due to an increase of the surface coverage of the metal by the additive molecules. Consequently the inhibition efficiency of dissolution of aluminum in hydrochloric acid solutions increases. It was found that for concentrations of the inhibitor higher than $10^{-4} \mathrm{M}$, time has little effect on the corrosion rate. This can be explained assuming that in such a solution the concentration of the inhibitor is sufficient to cover almost completely the metal surface and the rate of adsorption becomes slower, compared to that observed at lower concentrations.

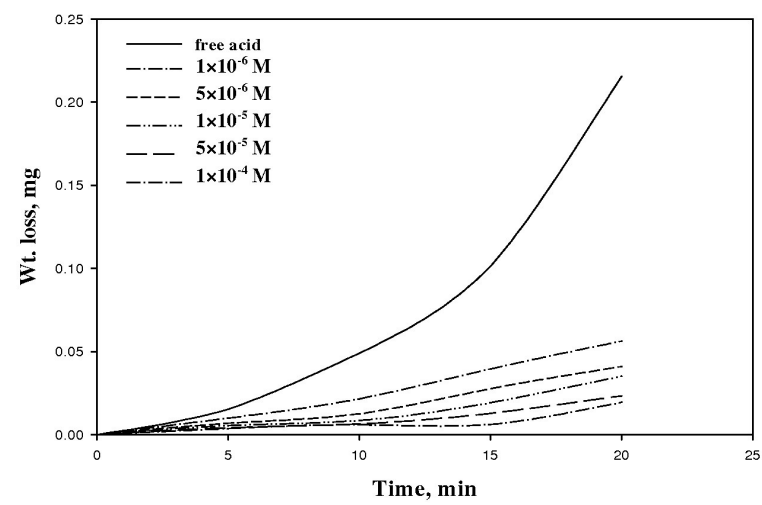

Fig. 2 The weight loss $v s$. time for aluminum corrosion in $2 \mathrm{M} \mathrm{HCl}$ in the presence of different concentrations of compound $\mathbf{I}$. 
The values of the corrosion rate and inhibition efficiency for the different azo dyes (Table 2) revealed that the decrease in corrosion rate and the increase in inhibition efficiency are more significant for the bisazo compounds (V-VIII) than for the mono-azo ones (I-IV). This may be due to the larger size of the bisazo molecules as compared with that of the mono-azo ones, which allows covering more surface area of the metal, as well as to the larger number of hydroxyl group which ensure strong bonding to the surface. The data also indicated that the 2,7-hydroxynaphthylazo and the o-methoxyphenylazo compounds decrease the corrosion rate, and consequently increase the inhibition efficiency, better than the 2,3-dihydroxynaphthylazo and o-carboxyphenylazo dyes. This may be connected with the ability of the electron-withdrawing carboxy group to lower the electron density on the azo group. This will destabilize the adsorption of inhibitor molecules on the metal surface, whereas the electron-donating methoxy group increases the electron density on the azo group. Besides, in the case of the carboxy group one sixmembered chelate ring is available, while in the case of the methoxy group two chelate rings are available, leading to a more stable complex. The decrease of the corrosion rate and increase of the inhibition efficiency follow the sequence VIII $>$ VII $>$ VI $>$ V $>$ IV $>$ III $>$ II $>$ I.

\subsection{Adsorption considerations}

The inhibition action of mono- and bis-azo compounds towards the corrosion of $\mathrm{Al}$ in $2 \mathrm{M} \mathrm{HCl}$, can be attributed to several factors, including the number and type of adsorption sites, the nature of the inhibitor molecules, the nature of the metal surface, and the ability to form complexes [19]. The inhibition mechanism of the azo compounds under investigation is believed to be the result of adsorption of inhibitor molecules, or their metal complexes, on the surface of the metal.

Adsorption depends mainly on the charge, the nature and the electronic characteristics of the metal surface, adsorption of solvent molecules and other ionic species, temperature, and the electrochemical potential at the solution-interface [20]. Adsorption isotherms are usually used to describe the type of adsorption process. The most frequently used isotherms include those named after Langmuir, Frumkin and Temkin. The establishment of adsorption isotherms that describe the adsorption of inhibitors can provide important clues to the nature of the metalinhibitor interaction. Adsorption of organic molecules occurs when the interaction energy between the inhibitor molecules and the metal surface is higher than that between the solvent molecules and the metal surface [21].

By far, the best fit for all of the azo compounds (I-VIII) was obtained with the Temkin isotherm, applying Eq. 8:

$$
\exp (-2 a \theta)=K C
$$

where $a$ is a constant related to the molecule, $\theta$ is the degree of surface coverage, $K$ is the equilibrium constant of the adsorption process, and $C$ is the concentration of the inhibitor. The plot of the surface coverage $\theta$ for the azo compounds I-VIII, as a function of the logarithm of the inhibitor concentration, is shown in Fig. 3. Straight lines were obtained, suggesting that the Temkin isotherm is obeyed for the adsorption of these azo compounds on the aluminum surface.

Fig. 3 shows a good data fit with a high linear correlation coefficient, $R^{2} \approx 0.97$. The standard free energy of the adsorption process $\Delta G_{\text {ads }}$ could be obtained from Eq. 9:

$$
K=\frac{1}{55.5} \exp \left[\frac{-\Delta G_{\text {ads }}}{\mathrm{R} T}\right]
$$

where 55.5 is the molar concentration of water in the solution in $\mathrm{mol} / \mathrm{l}, \mathrm{R}$ is the gas constant and $T$ is the absolute temperature. The values of $\Delta G_{\text {ads }}$ calculated from Eq. 9 ranged from -10.52 to $-10.91 \mathrm{~kJ} \mathrm{~mol}^{-1}$ at $30^{\circ} \mathrm{C}$. The negative and relatively small values of $\Delta G_{\text {ads }}$ indicated spontaneous adsorption of the inhibitor molecules on the metal surface and physical

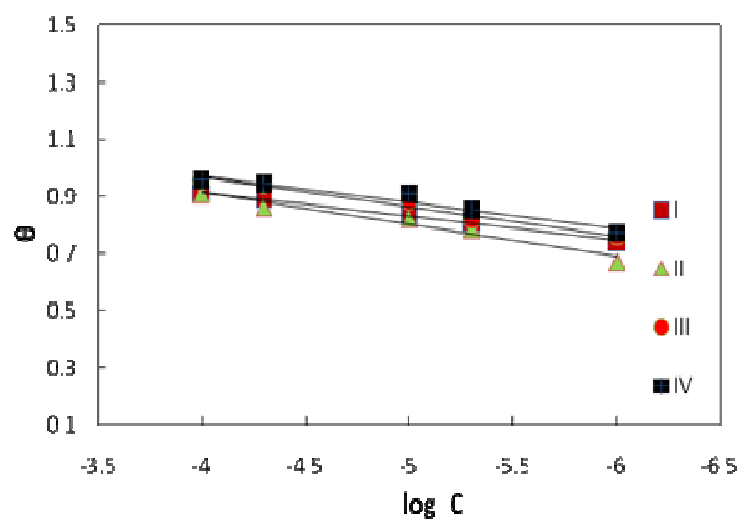

a

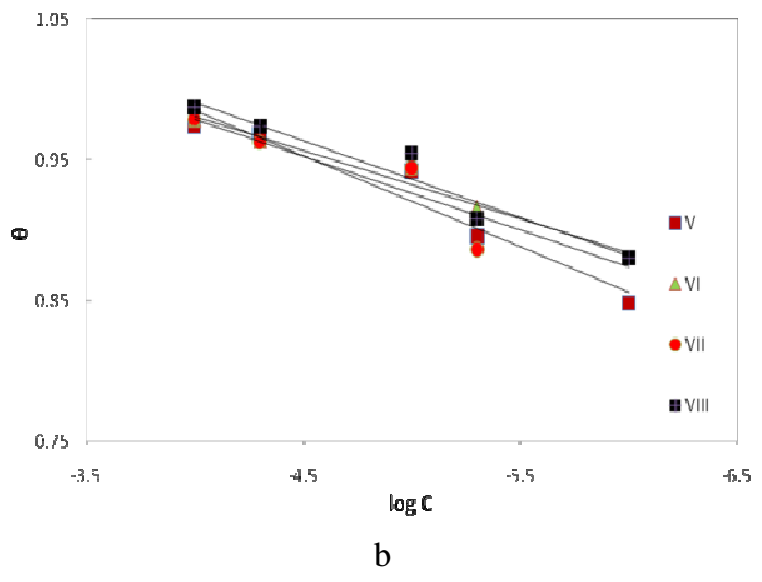

Fig. 3 Temkin adsorption isotherms of aluminum in $2 \mathrm{M} \mathrm{HCl}$ solutions: (a) inhibitors I-IV, (b) inhibitors V-VIII. 
E.M. Mabrouk et al., Inhibition of aluminum corrosion in acid solution by mono- and bis-azo naphthylamine dyes...

Table 3 Effect of the concentration of inhibitors I-VIII on the reaction number $(R N)$ and the inhibition efficiency $(I E)$ of aluminum in $2 \mathrm{M} \mathrm{HCl}$ solutions as determined by the thermometric technique.

\begin{tabular}{|c|c|c|c|c|c|c|c|c|}
\hline \multirow{2}{*}{$\begin{array}{c}\text { Concentration, } \\
\mathrm{M}\end{array}$} & \multicolumn{2}{|c|}{ I } & \multicolumn{2}{|c|}{ II } & \multicolumn{2}{|c|}{ III } & \multicolumn{2}{|c|}{ IV } \\
\hline & $R N$ & $I E$ & $R N$ & $I E$ & $R N$ & $I E$ & $R N$ & $I E$ \\
\hline 0.00 & 1.1 & - & 1.1 & - & 1.1 & - & 1.1 & - \\
\hline $1 \times 10^{-6}$ & 0.90 & 28.18 & 0.90 & 28.18 & 0.90 & 28.18 & 0.89 & 19.09 \\
\hline $5 \times 10^{-6}$ & 0.70 & 36.36 & 0.69 & 37.27 & 0.67 & 39.09 & 0.65 & 40.09 \\
\hline $1 \times 10^{-5}$ & 0.62 & 43.63 & 0.58 & 47.27 & 0.57 & 48.18 & 0.55 & 50.00 \\
\hline $5 \times 10^{-5}$ & 0.57 & 48.18 & 0.51 & 53.63 & 0.49 & 55.45 & 0.49 & 55.45 \\
\hline $1 \times 10^{-4}$ & 0.49 & 55.45 & 0.48 & 56.36 & 0.43 & 60.90 & 0.40 & 65.36 \\
\hline \multirow{2}{*}{$\begin{array}{c}\text { Concentration, } \\
\mathrm{M}\end{array}$} & \multicolumn{2}{|c|}{ V } & \multicolumn{2}{|c|}{ VI } & \multicolumn{2}{|c|}{ VII } & \multicolumn{2}{|c|}{ VIII } \\
\hline & $R N$ & $I E$ & $R N$ & $I E$ & $R N$ & $I E$ & $R N$ & $I E$ \\
\hline 0.00 & 1.1 & - & 1.1 & - & 1.1 & - & 1.1 & - \\
\hline $1 \times 10^{-6}$ & 0.85 & 22.72 & 0.83 & 24.54 & 0.77 & 30.00 & 0.75 & 31.81 \\
\hline $5 \times 10^{-6}$ & 0.63 & 42.72 & 0.62 & 43.63 & 0.61 & 44.54 & 0.61 & 44.54 \\
\hline $1 \times 10^{-5}$ & 0.44 & 60.00 & 0.44 & 60.00 & 0.44 & 60.00 & 0.43 & 60.90 \\
\hline $5 \times 10^{-5}$ & 0.32 & 70.90 & 0.32 & 70.90 & 0.32 & 70.90 & 0.32 & 70.90 \\
\hline $1 \times 10^{-4}$ & 0.31 & 71.81 & 0.30 & 72.72 & 0.30 & 72.73 & 0.29 & 73.63 \\
\hline
\end{tabular}

adsorption. Values of $\Delta G_{\text {ads }}$ up to $-20 \mathrm{~kJ} \mathrm{~mol}^{-1}$ are generally consistent with electrostatic interaction between charged molecules and a charged metal surface (which indicates physical adsorption), while values more negative than $-40 \mathrm{~kJ} \mathrm{~mol}^{-1}$ involve charge sharing or transfer of electrons from the inhibitor molecules to the metal surface to form bonds of coordinate type (which indicates chemisorption) [22].

\subsection{Thermometric measurements}

The effect of the concentration of the inhibitors I-VIII on the thermometric curves of aluminum in $2 \mathrm{M} \mathrm{HCl}$ solutions was studied and the results obtained for compound $\mathbf{I}$ are represented graphically in Fig. 4 as an example. Similar curves (not shown) were obtained for the other compounds. As shown in Fig. 4, the curves revealed that the dissolution of aluminum in $\mathrm{HCl}$ solution is characterized by an initial slow rise of temperature, followed by a sharp rise, and finally a decrease after attaining a maximum value. The initial slow rise, which characterizes the first part of the thermometric curves, may be due to an oxide film originally present on the metal surface, which protected it from reaction with the medium. As the concentration of additives increases, the time required to reach the maximum temperature $T_{\mathrm{m}}$ increases and, consequently, the rate of the temperature rise decreases. The maximum temperature measured for the free acid solution was $87^{\circ} \mathrm{C}$, which was attained after $\approx 45 \mathrm{~min}$. The reaction numbers of the azo compounds I-VIII at different concentrations were calculated using Eq. 5 and the extent of corrosion inhibition by a certain concentration of the additives (IE) was evaluated from the relative reduction of the reaction number $(R N)$, given by Eq. 6 (Table 3 ). The results indicated that the reaction number decreases with increasing concentration of inhibitor and consequently, the inhibition efficiency $(I E)$ increases.

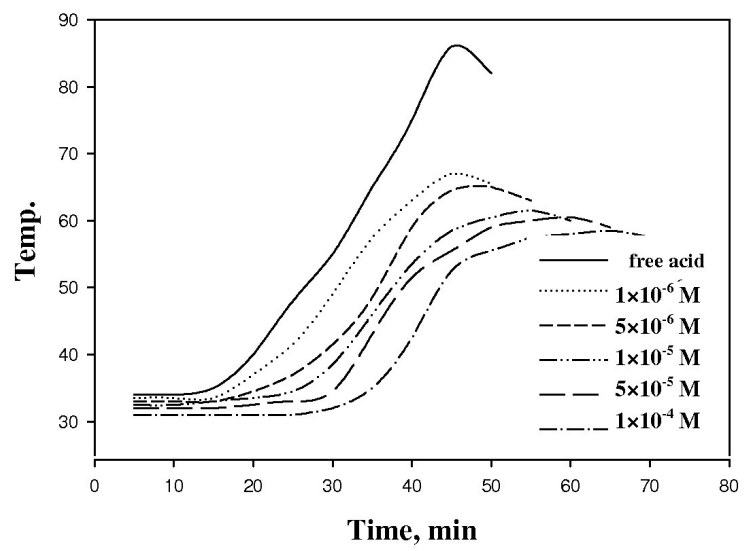

Fig. 4 Variation of temperature with time for aluminum in $2 \mathrm{M} \mathrm{HCl}$ solutions for different concentrations of compound $\mathbf{I}$.

\subsection{Galvanostatic polarization measurements}

Galvanostatic polarization measurements were carried out in $0.1 \mathrm{M} \mathrm{HCl}$ solutions, in the absence and in the presence of different concentrations of the inhibitors (I-VIII). Fig. 5 presents cathodic and anodic polarization curves for azo compound I. Similar curves (not shown) were obtained for the other azo compounds. Inspection of Fig. 5 reveals that an increase of the inhibitor concentration shifts the anodic curves to more positive potentials and the cathodic curves to more negative ones. This may be ascribed to adsorption of inhibitor molecules on the corroded metal surface.

The corrosion current density $\left(I_{\text {corr }}\right)$ was calculated by extrapolation of the anodic and cathodic Tafel lines with a steady state corrosion potential $\left(E_{\text {corr }}\right)$. The anodic Tafel slope $\left(\beta_{a}\right)$ and the cathodic Tafel slope $\left(\beta_{c}\right)$ were evaluated. The inhibition efficiency $(I E)$ and the surface coverage $(\theta)$ were calculated using Eqs. 6 
E.M. Mabrouk et al., Inhibition of aluminum corrosion in acid solution by mono- and bis-azo naphthylamine dyes...

Table 4 The effect of the concentration of inhibitors I-VIII on the free corrosion potential $\left(E_{\text {corr }}\right)$, corrosion current density $\left(I_{\text {corr }}\right)$, Tafel slopes $\left(\beta_{a}\right.$ and $\left.\beta_{c}\right)$, degree of surface coverage $(\theta)$, and inhibition efficiency $(I E)$ for the corrosion of aluminum in $2 \mathrm{M} \mathrm{HCl}$ at $30^{\circ} \mathrm{C}$.

\begin{tabular}{|c|c|c|c|c|c|c|c|}
\hline Compound & $\begin{array}{c}\text { Concentration, } \\
\mathrm{M} \\
\end{array}$ & $\begin{array}{c}-E_{\text {corr }}, \\
\mathrm{mV}(\mathrm{SCE})\end{array}$ & $\begin{array}{c}I_{\text {corr }}, \\
\mu \mathrm{A} \mathrm{cm}^{-2}\end{array}$ & $\begin{array}{c}-\beta_{c}, \\
\mathrm{mV} \mathrm{dec}^{-1}\end{array}$ & $\begin{array}{c}\beta_{a}, \\
\mathrm{mV} \mathrm{dec}^{-1}\end{array}$ & $\theta$ & $I E$ \\
\hline Blank & 0 & 730 & 69.6 & 89 & 78 & - & - \\
\hline \multirow[t]{5}{*}{ I } & $1 \times 10^{-6}$ & 727 & 50.4 & 103 & 81 & 0.276 & 27.58 \\
\hline & $5 \times 10^{-6}$ & 726 & 44.2 & 103 & 82 & 0.365 & 36.49 \\
\hline & $1 \times 10^{-5}$ & 725 & 41.2 & 104 & 82 & 0.408 & 40.80 \\
\hline & $5 \times 10^{-5}$ & 723 & 37.1 & 108 & 84 & 0.467 & 46.69 \\
\hline & $1 \times 10^{-4}$ & 722 & 33.2 & 110 & 84 & 0.477 & 47.70 \\
\hline \multirow[t]{5}{*}{ II } & $1 \times 10^{-6}$ & 724 & 46.2 & 102 & 82 & 0.336 & 33.62 \\
\hline & $5 \times 10^{-6}$ & 723 & 43.5 & 106 & 83 & 0.375 & 37.50 \\
\hline & $1 \times 10^{-5}$ & 718 & 40.2 & 107 & 85 & 0.422 & 42.24 \\
\hline & $5 \times 10^{-5}$ & 715 & 35.2 & 110 & 87 & 0.494 & 49.42 \\
\hline & $1 \times 10^{-4}$ & 715 & 32.3 & 113 & 88 & 0.536 & 53.59 \\
\hline \multirow[t]{5}{*}{ III } & $1 \times 10^{-6}$ & 723 & 42.2 & 106 & 83 & 0.394 & 39.36 \\
\hline & $5 \times 10^{-6}$ & 722 & 38.6 & 107 & 88 & 0.445 & 44.54 \\
\hline & $1 \times 10^{-5}$ & 722 & 35.4 & 108 & 91 & 0.491 & 49.13 \\
\hline & $5 \times 10^{-5}$ & 718 & 29.2 & 115 & 93 & 0.580 & 58.04 \\
\hline & $1 \times 10^{-4}$ & 715 & 27.2 & 117 & 94 & 0.609 & 60.91 \\
\hline \multirow[t]{5}{*}{ IV } & $1 \times 10^{-6}$ & 728 & 40.2 & 90 & 79 & 0.422 & 42.24 \\
\hline & $5 \times 10^{-6}$ & 726 & 36.2 & 91 & 80 & 0.480 & 47.98 \\
\hline & $1 \times 10^{-5}$ & 725 & 33.9 & 93 & 80 & 0.513 & 51.29 \\
\hline & $5 \times 10^{-5}$ & 723 & 28.2 & 103 & 82 & 0.595 & 59.48 \\
\hline & $1 \times 10^{-4}$ & 723 & 26.2 & 104 & 83 & 0.624 & 62.35 \\
\hline \multirow[t]{5}{*}{$\mathbf{V}$} & $1 \times 10^{-6}$ & 726 & 38.4 & 100 & 82 & 0.448 & 44.82 \\
\hline & $5 \times 10^{-6}$ & 725 & 35.2 & 102 & 83 & 0.494 & 49.42 \\
\hline & $1 \times 10^{-5}$ & 722 & 32.2 & 104 & 85 & 0.537 & 53.73 \\
\hline & $5 \times 10^{-5}$ & 721 & 26.6 & 110 & 86 & 0.618 & 61.78 \\
\hline & $1 \times 10^{-4}$ & 720 & 25.1 & 112 & 87 & 0.640 & 63.93 \\
\hline \multirow[t]{5}{*}{ VI } & $1 \times 10^{-6}$ & 719 & 35.5 & 103 & 81 & 0.490 & 48.99 \\
\hline & $5 \times 10^{-6}$ & 715 & 32.2 & 107 & 82 & 0.537 & 53.73 \\
\hline & $1 \times 10^{-5}$ & 712 & 29.7 & 108 & 84 & 0.573 & 57.32 \\
\hline & $5 \times 10^{-5}$ & 710 & 24.8 & 113 & 88 & 0.644 & 64.36 \\
\hline & $1 \times 10^{-4}$ & 708 & 22.7 & 114 & 91 & 0.674 & 67.38 \\
\hline \multirow[t]{5}{*}{ VII } & $1 \times 10^{-6}$ & 722 & 32.8 & 103 & 85 & 0.529 & 52.87 \\
\hline & $5 \times 10^{-6}$ & 725 & 30.7 & 106 & 87 & 0.559 & 55.89 \\
\hline & $1 \times 10^{-5}$ & 722 & 27.5 & 109 & 90 & 0.605 & 60.48 \\
\hline & $5 \times 10^{-5}$ & 715 & 22.3 & 114 & 94 & 0.679 & 67.95 \\
\hline & $1 \times 10^{-4}$ & 710 & 20.7 & 116 & 96 & 0.703 & 70.25 \\
\hline \multirow[t]{5}{*}{ VIII } & $1 \times 10^{-6}$ & 725 & 30.4 & 102 & 83 & 0.563 & 56.32 \\
\hline & $5 \times 10^{-6}$ & 722 & 28.3 & 105 & 85 & 0.593 & 59.33 \\
\hline & $1 \times 10^{-5}$ & 720 & 25.2 & 108 & 85 & 0.638 & 63.79 \\
\hline & $5 \times 10^{-5}$ & 715 & 20.2 & 112 & 88 & 0.710 & 70.97 \\
\hline & $1 \times 10^{-4}$ & 713 & 18.4 & 114 & 90 & 0.736 & 73.56 \\
\hline
\end{tabular}

and 7 and are listed in Table 4. The data given in Table 4 revealed that both $\beta_{a}$ and $\beta_{c}$ increase slightly with increasing concentration of the inhibitors I-VIII, indicating that these compounds affect both the anodic and cathodic reactions. Therefore, the hydroxynaphthaleneazo compounds I-VIII can be considered as mixed inhibitors. The corrosion current $\left(I_{\text {corr }}\right)$ decreases and the inhibition efficiency (IE) increases with increasing concentration of inhibitor.

The values of $I E$ calculated for the acid corrosion of aluminum using the three different techniques showed a good agreement and confirmed the conformity of the experimental results. The observed discrepancies could be attributed to the different experimental conditions under which each technique was carried out.

The results obtained from the three different techniques revealed that $I E$ depends on the type of inhibitor (mono-azo or bis-azo), the position of the hydroxyl groups in the naphthyl ring and the type of substituent. It is clear that the corrosion rate decreases and the inhibition efficiency increases markedly in the 


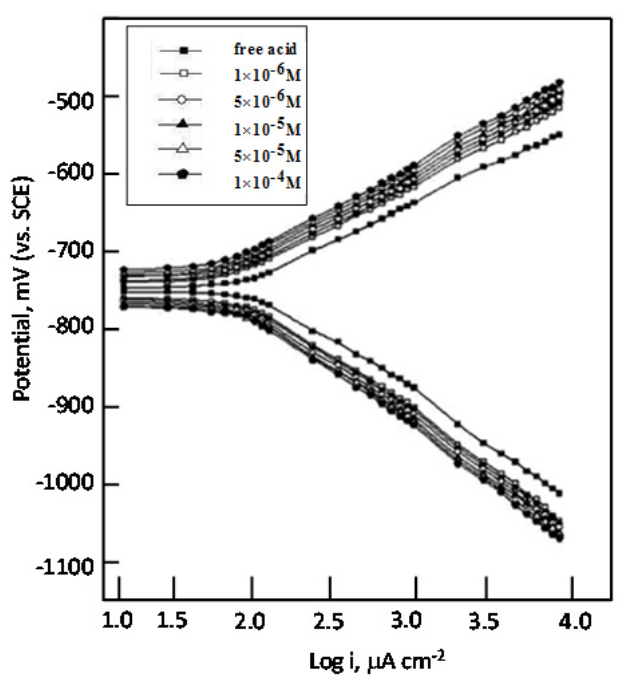

Fig. 5 Galvanostatic polarization curves for the corrosion of aluminum in $2 \mathrm{M} \mathrm{HCl}$ for different concentrations of compound $\mathbf{I}$.

Table 5 Thermodynamic activation parameters of corrosion of aluminum in free and inhibited $2 \mathrm{M} \mathrm{HCl}$ acid solutions at $30^{\circ} \mathrm{C}$.

\begin{tabular}{l|c|c}
\hline \multicolumn{1}{c|}{ Compd. } & $-E_{\mathrm{a}}{ }^{*}, \mathrm{~kJ} \mathrm{~mol}^{-1}$ & $-\Delta H^{*}, \mathrm{~kJ} \mathrm{~mol}^{-1}$ \\
\hline Free acid & 44.95 & 42.26 \\
I & 48.74 & 46.06 \\
II & 54.88 & 52.20 \\
III & 56.21 & 53.53 \\
IV & 57.46 & 55.61 \\
V & 59.79 & 57.11 \\
VI & 62.14 & 59.45 \\
VII & 65.88 & 63.20 \\
VIII & 69.85 & 67.16 \\
\hline
\end{tabular}

case of the bis-azo compounds, in comparison with the mono-azo ones. This may due to the larger size of the bis-azo molecule, which covers a larger surface area of the metal, as well as to the greater number of hydroxyl groups, which are strongly bonded the surface. In addition, the results indicate that the 2,7-dihydroxynaphthylazo and o-methoxyphenylazo compounds decrease the corrosion rate, and consequently increase the inhibition efficiency, more than the 2,3-dihydroxynaphthylazo and o-carboxyphenylazo compounds.

\subsection{Thermodynamic considerations}

The effect of temperature on the corrosion rate of $\mathrm{Al}$ in a $2 \mathrm{M} \mathrm{HCl}$ solution, in the absence and in the presence of $1 \times 10^{-4} \mathrm{M}$ of the selected inhibitors, was studied by weight loss measurements at 40, 50 and $60^{\circ} \mathrm{C}$. It is clear that the corrosion rate increases with increasing temperature. This indicates that an increase of the temperature decreases the inhibition efficiency and the best inhibition efficiency was obtained at $40^{\circ} \mathrm{C}$.

A plot of the logarithm of the corrosion rate of aluminum obtained from weight loss measurements vs. 1000/T gave straight lines, as shown in Fig. 6. The apparent activation energy $\left(E_{\mathrm{a}}{ }^{*}\right)$ was calculated by using the following relationship [23]:

$r=A \exp \left[\frac{E_{\mathrm{a}} *}{\mathrm{R} T}\right]$

$\log r=\log A-E_{\mathrm{a}} * / 2.303 \mathrm{R} T$

where $E_{\mathrm{a}} *$ is the apparent activation energy for the corrosion of aluminum in $2 \mathrm{M} \mathrm{HCl}$ solutions, $\mathrm{R}$ the general gas constant, $A$ the Arrhenius pre-exponential factor and $T$ is the absolute temperature. The values of $E_{\mathrm{a}}{ }^{*}$ obtained from the slopes of these lines are given in Table 5.

From the values of the Arrhenius constant and the activation energy, it is evident that the degree of linearity of the lines on the Arrhenius plots is very close to unity, indicating strong adherence of the experimental data to the Arrhenius theory. Secondly, the value of the activation energy for the blank solution was lower than those obtained for the solutions containing inhibitors, indicating that monoazo and bis-azo compounds deferred the corrosion of $\mathrm{Al}$ in $\mathrm{HCl}$ solutions. Lastly, the activation energies were lower than the threshold value of $80 \mathrm{~kJ} / \mathrm{mol}$ required for chemical adsorption, hence the adsorption of mono-azo and bis-azo compounds on the $\mathrm{Al}$ surface is consistent with a mechanism of physical adsorption.

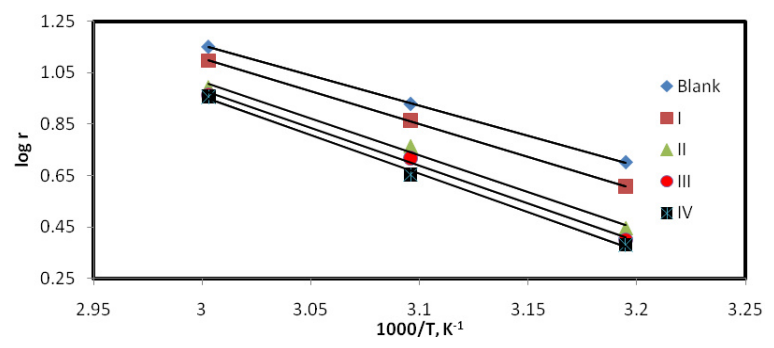

$\mathrm{a}$

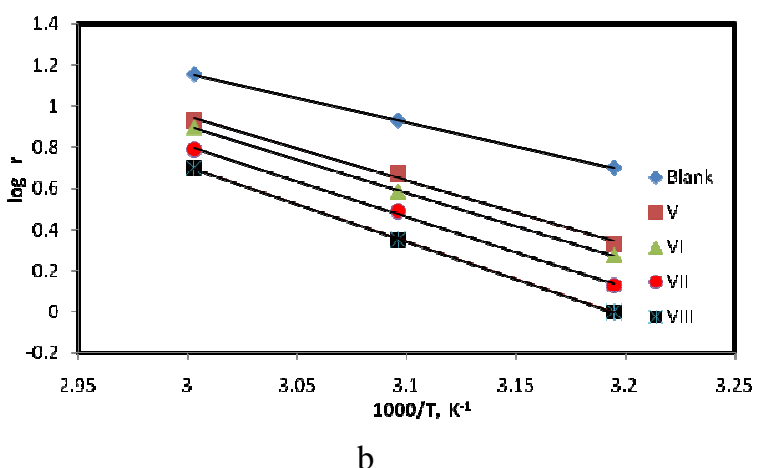

Fig. 6 Arrhenius plots of the corrosion rate of aluminum in $2 \mathrm{M} \mathrm{HCl}$ in the absence and in the presence of (a) inhibitors I-IV and (b) inhibitors V-VIII. 


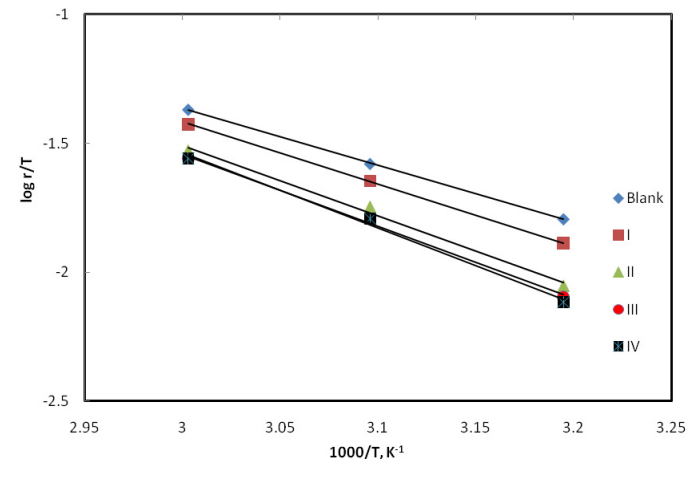

$\mathrm{a}$

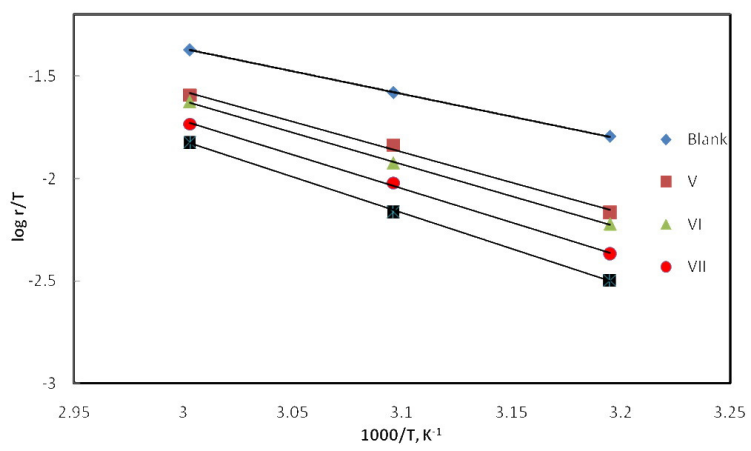

b

Fig. 7 Transition state plots of the corrosion rate of aluminum in $2 \mathrm{M} \mathrm{HCl}$ in the absence and in the presence of (a) inhibitors (I-IV) and (b) inhibitors (V-VIII).

An alternative formulation of the Arrhenius equation is the transition state equation [24]:

$r=\frac{\mathrm{R} T}{\mathrm{~N} h} \exp \frac{\Delta S^{*}}{\mathrm{R}} \exp \left[\frac{-\Delta H^{*}}{\mathrm{R} T}\right]$

where $\mathrm{h}$ is the Planck constant, $\mathrm{N}$ the Avogadro number, $\Delta S^{*}$ the entropy of activation, and $\Delta H^{*}$ the enthalpy of activation. Rearranging and taking the logarithm of both sides of Eq. 12 yields Eq. 13:

$\log \frac{r}{T}=\log \frac{\mathrm{R}}{\mathrm{N} h}+\frac{\Delta S^{*}}{2.303 \mathrm{R}}-\left[\frac{\Delta H^{*}}{2.303 \mathrm{R} T}\right]$

According to Eq. 13, a plot of $\log (r / T)$ vs. 1000/T should produce a straight line with a slope equal to $\Delta H^{*} / 2.303 R$. Fig. 7 illustrates the general features of the plots of $\log (r / T)$ vs. $1000 / T$, from which the values of $\Delta H^{*}$ listed in Table 5 were calculated. The data show that the thermodynamic activation functions $\left(E_{\mathrm{a}}^{*}\right.$ and $\left.\Delta H^{*}\right)$ of the corrosion of aluminum in $2 \mathrm{M}$ $\mathrm{HCl}$ solution in the presence of the inhibitors are higher than for the free acid solutions. The adsorption of the inhibitors is assumed to occur on the higher energy sites and the presence of the inhibitor, which results in blocking of active sites, must be associated with an increase of the activation energy of aluminum corrosion in the inhibited state [25]. The values of $\Delta H^{*}$ are negative, indicating that the adsorption of the inhibitors on the surface of the metal is exothermic [26-28], and range from -42 to $-67 \mathrm{~kJ} / \mathrm{mol}$ at $40^{\circ} \mathrm{C}$.

\section{Conclusions}

Hydroxynaphthaleneazo dye compounds inhibit the corrosion of $\mathrm{Al}$ in $2 \mathrm{M} \mathrm{HCl}$ solutions. The inhibition efficiency of these compounds increased with increasing concentration of the inhibitor, increasing electron donor characteristic of the substituted groups, and decreasing temperature. The inhibition action of these compounds is attributed to adsorption of inhibitor molecules on the metal surface. The adsorption process was found to obey the Temken adsorption isotherm. The order of increasing inhibition efficiency for the investigated compounds is I $<$ II $<$ III $<$ IV $<$ V $<$ VI $<$ VII $<$ VIII. The additives influence both the cathodic and the anodic reactions in the $\mathrm{HCl}$ solution. This indicates that the additives act as mixed-type inhibitors.

\section{References}

[1] M. Abdallah, Corros. Sci. 46 (2004) 1981.

[2] A.Y. El-Etre, H.E. Megahed, M. Abdallah, M.A. Obied, Corros. Prev. 32, March (2004).

[3] S.S. Abd El-Rehim, H.H. Hassan, M.A. Amin, Mater. Chem. Phys. 78 (2002) 337.

[4] M.L. Zheludkevich, K.A. Yasaku, S.K. Poznyak, M.G.S. Ferreira, Corros. Sci. 47 (2005) 3368.

[5] M.M. Osman, S.S. Abd El-Rehim, Mater. Chem. Phys. 53 (1998) 34.

[6] G.K. Gomma, M.H. Wahdan, Mater. Chem. Phys. 39 (1995) 209.

[7] M. Abdallah, Bull. Electrochem. 16(6) (2000) 258.

[8] M. Abdalla, H.E. Meguhid, A.Y. El-Etre, M.A. Obied, E.M. Mabrouk, Bull. Electrochem. 20(6) (2004) 277.

[9] K.S. Khairou, A.A. Alfi, E.M. Mabrouk, Mater. Sci. Res. Indian 3(2a) (2006) 155.

[10] M.R. Saleh, A.M. Shams El-Din, Corros. Sci. 21(6) (1981) 439.

[11] F. Bentiss, M. Lagrence, M. Traisnel, J.C. Hornez, Corros. Sci. 41 (1999) 789.

[12] V.S. Sastry, Corrosion Inhibitors, Principles and Applications, John Wiley \& Sons, New York, 1998.

[13] F. Bentiss, M. Lagrence, M. Traisnel, Corros. 56 (2000) 733.

[14] F. Bentiss, M. Traisnel, M. Lagrence, J. Appl. Electrochem. 31 (2001) 41.

[15] J.B. Conant, R.E. Lutz, B.B. Corson, Organic Syntheses, Coll. Vol. 1, John Wiley \& Sons, New York, 1941, p. 49. 
E.M. Mabrouk et al., Inhibition of aluminum corrosion in acid solution by mono- and bis-azo naphthylamine dyes...

[16] P.B. Mathur, T. Vasudevan, Corros. 38 (1982) 17

[17] R.J. Chin, K. Nobe, J. Electrochem. Soc. 118 (1971) 545.

[18] F.Z. Mylius, Z. Metallkd. 14 (1922) 233.

[19] A.S. Fouda, M. Mousa, F.Taha, A. El-Neanaa, Corros. Sci. 26 (1986) 719.

[20] I.L. Rozendeld, Corrosion Inhibitors, Mc GrawHill, New York, 1981.

[21] G. Quartarone, G. Moretti, A. Tassan, A. Zingales, Werkst. Korros. 45 (1994) 34.

[22] P.C. Okafor, E.E. Ebenso, U.J. Ibok, U.J. Ekpe, M.I. Ikpi, Trans. SAEST 38 (2003) 91.
[23] G. Trabanelli, In: F. Mansfeld (Ed.), Corrosion Mechanisms, Marcel Dekker, New York, 1987, p. 119.

[24] S. Sayed, E.R. Abd, H.H. Hamdy, A.A. Mohammed, Mater. Chem. Phys. 70 (2001) 64.

[25] A.S. Founda, A. Abd El-Aal, A.B. Kandil, Desalination 201 (2006) 216.

[26] E.E. Ebenso, Mater. Chem. Phys. 79 (2003) 58.

[27] E.E. Ebenso, Bull. Electrochem. 19 (2003) 209.

[28] H.M. Bhajiwala, R.T. Vashi, Bull. Electrochem. 17 (2001) 441. 